\title{
Molded Vial Manufacturing and Its Impact on Heat Transfer during Freeze-Drying: Vial Geometry Considerations
}

\author{
Tim Wenzel ${ }^{1,2}$ and Henning Gieseler ${ }^{1,2,3}$
}

Received 23 November 2020; accepted 6 January 2021; published online 27 January 2021

\begin{abstract}
Recent advances in molded vial manufacturing enabled manufacturers to use a new manufacturing technique to achieve superior homogeneity of the vial wall thickness. This study evaluated the influence of the different manufacturing techniques of molded vials and glass compositions on vial heat transfer in freeze-drying. Additionally, the influence of using empty vials as thermal shielding on thermal characteristics of edge and center vials was investigated. The vial heat transfer coefficient $K_{\mathrm{v}}$ was determined gravimetrically for multiple vial systems. The results showed superior heat transfer characteristics of the novel manufacturing technique as well as differences in heat transfer for the different glass compositions. Empty vials on the outside of the array did not influence center vial $K_{\mathrm{v}}$ values compared to a full array. The direct contact area and vial bottom curvature and their correlation to heat transfer parameters were analyzed across multiple vial systems. A new approach based on light microscopy to describe the vial bottom curvature more accurately was described. The presented results for the contact area allowed for an approximation of the pressure-independent heat transfer parameter $\mathrm{KC}$. The results for the vial bottom curvature showed a great correlation to the pressure-dependent heat transfer parameter KD. Overall, the results highlighted how a thorough geometrical characterization of vials with known heat transfer characteristics could be used to predict thermal characteristics of new vial systems as an alternative to a time-consuming gravimetric $K_{\mathrm{v}}$ determination. Primary drying times were simulated to show the influence of $K_{\mathrm{v}}$ on drying performance.
\end{abstract}

KEY WORDS: freeze-drying; lyophilization; heat transfer; molded vials; vial geometry.

\section{INTRODUCTION}

Glass vials are the most common primary packaging material used in pharmaceutical freeze-drying (1). Depending on the manufacturing process, tubing or molded vials can be distinguished in the market. The practical relevance of each vial type depends on the fill volume of the product: smallvolume parenterals are typically freeze-dried in tubing vials while molded vials are primarily used for products with higher fill volumes (2). The manufacturing process of tubing vials is a two-step process with glass tubes as an intermediary product. The manufacturing process for molded vials is also routinely performed in two steps: first, the molten glass is formed into an initial parison with a defined opening and a hollow inside. Second, this parison is transferred into a

\footnotetext{
${ }^{1}$ Department of Pharmaceutics, Freeze Drying Focus Group (FDFG), Friedrich-Alexander University (FAU) Erlangen-Nuremberg, Cauerstrasse 4, 91058, Erlangen, Germany.

${ }^{2}$ GILYOS GmbHI, Friedrich-Bergius-Ring 15, 97076, Würzburg, Germany.

${ }^{3}$ To whom correspondence should be addressed. (e-mail: info@gilyos.com)
}

second mold where the final shape of the vial is formed by blowing the parison with compressed air. The formation of the initial parison in the first mold can either be performed by blowing the molten glass with compressed air ("blow-blow," further abbreviated as BB) or pressing it with a metal plunger ("press-blow," further abbreviated as PB). The PB process results in vials with a more uniform glass distribution and wall thickness. However, due to challenges with the plunger design for narrow-necked containers, it has historically been limited to more wide-necked containers (3). Recent advances in vial manufacturing have allowed manufacturers to produce smaller PB molded vials down to a size of $15-\mathrm{mL}$ injection vials (4).

The thermal performance of a container system is of utmost importance to the freeze-drying process. Heat needs to be efficiently transferred between the heat transfer fluid inside the shelves and the product inside the container $(5,6)$. During the freezing stage, heat from the freezing solution needs to be removed to adequately cool the product to its target freezing temperature. The sublimation process during drying requires energy to be transferred into the product. The heat transfer coefficient describes the rate of energy transfer per area, temperature differential, and time between the 
freeze-dryer and the container system $(5,7)$. The coefficient for vial freeze-drying is referred to as the vial heat transfer coefficient $K_{\mathrm{v}}$. Representative $K_{\mathrm{v}}$ values are essential for a quality by design (QbD) approach to develop or transfer freezedrying cycles: the calculation of the design space requires $K_{\mathrm{v}}$ as an input parameter (8-11). Knowledge of $K_{\mathrm{v}}$ values for different machines can be used for the adaptation of process parameters during scale-up or transfer of freeze-drying cycles to reduce the number of experiments required for successful transfer (12-14). Several tools for the modeling of the freeze-drying process or a simulation of process parameters, for example the PASSAGE or SCANPT softwares or the LyoModelling Calculator, require $K_{\mathrm{v}}$ as an input parameter (15-17).

$K_{\mathrm{v}}$ can be determined by several methods. The gravimetric approach is the simplest procedure and has been used over the decades. It relies on the determination of the mass loss over time by weighing the vials before and after the experiment $(2,18)$. Some technologies, such as Manometric Temperature Measurement (MTM; 19) or Tunable Diode Laser Absorption Spectroscopy (TDLAS; 20,21) can calculate $K_{\mathrm{v}}$ based on process parameters and steady-state heat and mass transfer models. AccuFlux ${ }^{\circledR}$ sensors, a type of adhesive probe that is placed on the shelf, can estimate $K_{\mathrm{v}}$ in a defined shelf area by measuring the temperature differential between shelf surface and vial bottom (22). The gravimetric approach is still considered the gold standard the other technologies are compared to for assessing their accuracy. While it is the most time-consuming method, it is the only method available that provides data for each individual vial located within a shelf load of vials (mapping). It should be kept in mind that even within one type of method (e.g., the gravimetric method), several factors can influence the obtained $K_{\mathrm{v}}$ values. For example, Hibler et al. (2) evaluated the influence of including the ramping phase before the steady state of ice sublimation in the $K_{\mathrm{v}}$ calculation. They concluded that the difference in $K_{\mathrm{v}}$ measured with or without the ramping phase increases at higher chamber pressures or lower sublimation times. Wegiel et al. (18) investigated the influence of the shelf temperature on the obtained $K_{v}$ values and found that the shelf temperature can significantly influence the observed edge vial $K_{\mathrm{v}}$ values with lower shelf temperatures leading to a more pronounced difference between edge and center vials. Different results on the importance of radiation shielding have been published so far: Tang et al. (19) reported lower $K_{\mathrm{v}}$ values with the gravimetric approach and using aluminum foil as a radiation shield on the inside of the freeze-dryer door while Wegiel et al. (18) reported no significant differences in their experiments with or without the radiation shield. Results obtained from different types of methods may vary in their accuracy. Tang et al. (19) reported a bias towards higher $K_{\mathrm{v}}$ values with MTM compared to the gravimetric approach. Kuu et al. (20) concluded that the difference they observed between their values and values provided in the literature (5) may be caused by different measurement approaches. Additionally, $K_{\mathrm{v}}$ values can be influenced by design features of the freeze-dryer that need to be taken into account during the scale-up or transfer of freeze-drying cycles (e.g., chamber wall emissivity or shelf separation distance; 14).

Apart from the experimental method, several vial specific factors can influence $K_{v}$. The type of vial (glass or polymer, molded or tubing) is known to have an influence on the thermal characteristics of the container system. Hibler et al. (2) found improved $K_{\mathrm{v}}$ homogeneity for polymer vials made of a cyclic olefin copolymer and similar performance compared to a molded vial of the same size. Different results on the effect of the glass composition have been published so far: Cannon et al. (23) reported significantly different sublimation rates for clear and amber glass vials of the same size while Hibler et al. (2) reported identical $K_{\mathrm{v}}$ values for a different pair of geometrically identical clear and amber vials. Generally, higher $K_{\mathrm{v}}$ values have been reported for tubing vials compared to molded vials due to the lower vial bottom curvature of tubing vials $(2,5,20)$. Consequently, it is recommendable that $K_{\mathrm{v}}$ values should always be reported for a specific vial and freeze-dryer combination with an exact description of how the values were obtained.

The influence of the PB manufacturing technique on molded vial $K_{\mathrm{v}}$ has not been evaluated so far. This study compares $K_{\mathrm{v}}$ of molded vials manufactured by the BB and PB techniques for the first time. Additionally, the influence of two different clear glass compositions and the effect of shelf load on $K_{\mathrm{v}}$ are studied. By comparing the $K_{\mathrm{v}}$ data with geometrical data of the investigated vial systems, a model for the calculation of heat transfer parameters based on geometrical data is proposed. A previous quantitative study on the impact of geometrical vial features by Scutella et al. (24) successfully translated the variability of the vial bottom geometry into $K_{\mathrm{v}}$ and product temperature heterogeneity for one tubing vial type. The authors used a semi-spherical calotte model to describe the vial bottom curvatures. Brüls et al. (25) investigated one type of tubing vials and used polynomials to describe the shape of the vial bottom. They differentiated between high and low curvature vials and showed a pressure-dependent influence of curvature on product temperatures. We proposed an alternative method to describe the vial bottom curvature that accounts for the asymmetry of the vial bottom and evaluated its applicability across different vial systems.

\section{MATERIALS AND METHODS}

\section{Materials}

All vials were obtained from SGD S.A. (Puteaux, France). Three different types of molded vials with a nominal fill volume of $20 \mathrm{~mL}$ were used in this study: $20-\mathrm{mL}$ vials manufactured by a BB process (" $20-\mathrm{mL}$ BB"), by a PB process with the same manufacturing mold as the $\mathrm{BB}$ vials ("20-mL PB1"), and by a PB process with from a freezedrying perspective optimized geometrical features (" $20-\mathrm{mL}$ PB2"). Two 50-mL vials with different clear glass compositions manufactured by a $\mathrm{PB}$ process in the same molds ("50-mL PB1" and "50-mL PB2") were analyzed. Additionally, 20-mL serum tubing vials were analyzed ("20-mL ST") for comparison.

$20 \mathrm{~mm}$ bromobutyl igloo stoppers by West Pharmaceutical Services (Eschweiler, Germany) and $32 \mathrm{~mm}$ bromobutyl cruciform stoppers by Datwyler Pharma Packaging International (Alken, Belgium) were used in the experiments. The sublimation experiments were performed with Water for 
Injection (WFI) by B Braun (Melsungen, Germany). Temperatures were monitored with calibrated 36 AWG thin-wire type $\mathrm{T}$ thermocouples (TCs) from OMEGA Engineering (Deckenpfronn, Germany). The vials were weighed on a calibrated XP205DR analytical balance (Mettler Toledo GmbH, Gießen, Germany).

\section{Methods}

\section{Geometrical Characterization of Vial Systems}

Imprint tests were performed on all vial systems to visualize the contact area with an even surface. Three different vials of each vial system were pressed on an inkpad and subsequently imprinted on a white sheet of paper (2). The direct contact area $A_{\mathrm{c}}$ was calculated similarly to Scutella et al. (24): the images were analyzed with ImageJ v1.53a (National Institutes of Health, Bethesda, MD; 26). Imprint images were converted into binary for better differentiation between contact and non-contact pixels. $A_{\mathrm{c}}$ was calculated by dividing the total imprint area by the total number of pixels of the vial imprint and multiplying it by the number of contact pixels. For data analysis, $A_{\mathrm{c}}$ was normalized to the contact area relative to the vial outer cross-sectional area $A_{\mathrm{v}}$ to allow comparisons between vial sizes. This was necessary to allow a comparison to heat transfer-related parameters that were also calculated in relation to $A_{\mathrm{v}}$.

The vials were laterally cut to compare the vial wall thickness homogeneity of the different vial types. Additionally, measurements of the vial bottom curvature were performed on seven laterally cut vials of each type. The maximum curvature of the vial bottom $\left(l_{\max }\right)$ and the effective separation distance of the vial bottom to a flat surface $\left(l_{\text {eff }}\right)$ were obtained. $l_{\text {eff }}$ was defined as the gas volume enclosed by the vial bottom curvature divided by the total area of the vial bottom. The determination of $l_{\text {eff }}$ is illustrated in Fig. 1: the vial bottom was traced under a light microscope. A coordinate system was applied so that the ordinate touches the contact points of the vial bottom. At a minimum, ten coordinates corresponding to the bottom curvature were recorded. The direct connection between the recorded coordinates served as an approximation of the vial bottom geometry. The obtained data points were split in half and the middle of the vial bottom defined as $y=0$. This resulted in two separate sets of linear functions starting on the ordinate at the data point corresponding to the left and right curvature edges, respectively, and ending on the abscissa in the middle of the vial. The volume of the solids of revolution for each set of linear functions was calculated by the disk method. The average of both obtained volumes was calculated to account for the asymmetry in the vial bottom geometry. This volume was divided by the total area of the vial bottom curvature to obtain $l_{\text {eff }}$ for each vial type. In short, $l_{\text {eff }}$ describes the height of a cylinder with an equal volume as the vial bottom concavity. The method with multiple linear functions was preferred over the previously described semi-spherical calotte model or polynomials because most vials did not feature a semi-spherical concavity and small irregularities (e.g., engraving in the vial bottom, asymmetrical vial shape) could be reflected more accurately $(24,25)$.

\section{Gravimetric $K_{v}$ Determination}

Experimental Procedure and $K_{v}$ Calculation. The experimental design was adapted based on a previous study (2). The vials were positioned in a hexagonal packaging array. The outermost row of vials was left empty and served as radiation shielding. The remaining vials were filled with $4.5 \mathrm{~mL}$ WFI for $20-\mathrm{mL}$ vials or $12 \mathrm{~mL}$ for $50-\mathrm{mL}$ vials and carefully semi-stoppered. The outmost vials filled with WFI are referred to as "edge vials" while the middle ones are addressed as "center vials".

The sublimation experiments were performed on a LyoStar $^{\mathrm{TM}}$ freeze-dryer (SP Scientific, Gardiner, NY) with the process parameters shown in Table I. These are identical to those used by Hibler et al. (2) to allow for better comparability of the obtained data. The chamber door was covered with aluminum foil on the inside of the drying chamber. Vials were immediately stoppered to stop sublimation at the end of each experiment. The vials were weighed after the ice was thawed to prevent humidity condensing on the vial surfaces and the cold temperature influencing the balance.

$K_{\mathrm{v}}$ in cal s${ }^{-1} \mathrm{~cm}^{-2} \mathrm{~K}^{-1}$ was calculated with Eq. 1 (2):

$K_{v}=\frac{d m / d t \times \Delta H_{s}}{A_{v} \times\left(T_{s, \text { surface }}-T_{b}\right)}$

where $d m / d t$ is the sublimation rate $(\mathrm{g} / \mathrm{s}), \Delta H_{\mathrm{s}}$ is the heat required for ice sublimation $(660 \mathrm{cal} / \mathrm{g}, 5), A_{\mathrm{v}}$ is the vial outer cross-sectional area $\left(\mathrm{cm}^{2}\right), T_{\mathrm{s}}$, surface is the average shelf surface temperature $(\mathrm{K})$, and $T_{\mathrm{b}}$ is the average product temperature at the vial bottom $(\mathrm{K})$. The reader is advised that $\Delta H_{\mathrm{s}}$ is temperature dependent with values ranging from 660 to $680 \mathrm{cal} / \mathrm{g}$ reported in the literature $(5,27)$. The impact of different $\Delta H_{\mathrm{s}}$ values on the calculated $K_{\mathrm{v}}$ values is small $(<3 \%)$. The value of $660 \mathrm{cal} / \mathrm{g}$ was adopted in this study for better comparability to the study by Hibler $e$ al. (2). $A_{\mathrm{v}}$ was calculated from the outer diameter of the vials determined with a calibrated caliper $\left(A_{\mathrm{v}, 20 \mathrm{~mL} \text { Molded }}=8.09 \mathrm{~cm}^{2}, A_{v, 50 \mathrm{~mL}}\right.$ Molded $\left.=16.58 \mathrm{~cm}^{2}, A_{\mathrm{v}}, 20 \mathrm{~mL} \mathrm{sT}=7.03 \mathrm{~cm}^{2}\right) . T_{S}$, surface was determined with two adhesive TCs attached near the shelf fluid inlet and outlet. The reader is advised that the sublimative cooling effect can have a small influence on $T_{\mathrm{s}}$, surface. This was accounted for by using the average of both TCs for calculations. $T_{\mathrm{b}}$ was measured invasively at the vial bottom in the center of the vial with TCs. $T_{\mathrm{b}}$ values were obtained from three probed center and edge vials, respectively.

Sublimation experiments were performed twice $(n=2)$ at each pressure setpoint. Because Eq. 1 is only valid during the steady state of primary drying, an additional experiment to determine the mass loss in the initial part of the sublimation phase was performed at each pressure setpoint (2). The steady state was assumed to be reached within $30 \mathrm{~min}$ of reaching the final shelf temperature setpoint (28). The experiment was stopped at that moment and the mass loss was determined. By subtracting the mass loss during the initial part from the total mass loss in the sublimation 

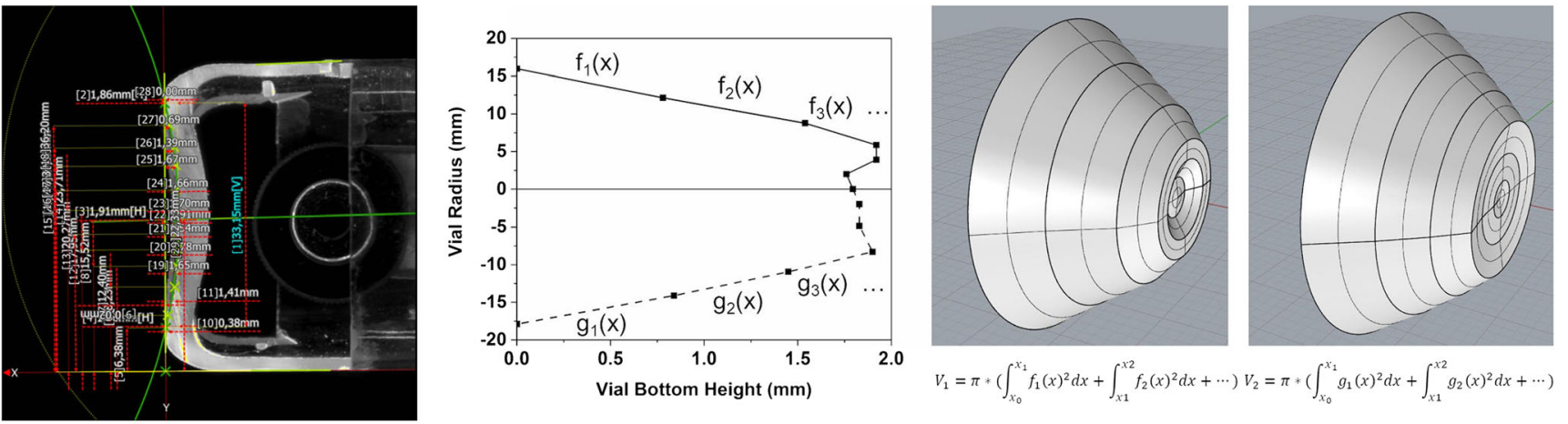

Fig. 1. Schematic overview of the $l_{\text {eff }}$ calculation procedure based on laterally cut vials

experiments, parameters exclusively for the steady-state period of primary drying were obtained for Eq. 1.

Additionally, the influence of the shelf load on the determined $K_{\mathrm{v}}$ values was investigated. Two additional sublimation experiments with the $20-\mathrm{mL}$ PB2 vials were performed at low and high chamber pressures (50 and 200 mTorr) with a full vial array and the results were compared to the data from the experiments with the empty row of vials on the outside.

Data Analysis. Data was analyzed by non-linear regression using Origin (Version 2019, OriginLab Corporation, Northampton, MA). Equation 2 was fitted to the data and used to dissect $K_{\mathrm{v}}$ into parameters describing the pressureindependent and pressure-dependent contributions to total $K_{\mathrm{v}}$ as described in the literature $(2,28)$ :

$K_{v}=K C+\frac{K P \times P}{1+K D \times P}$

where $K C$ is the parameter describing the sum of conductive and radiative heat transfer $\left(\mathrm{cal} \mathrm{s}^{-1} \mathrm{~cm}^{-2} \mathrm{~K}^{-1}\right), K P$ is a constant for glass vial systems $\left(3.32 \times 10^{-3} \mathrm{cal} \mathrm{s}^{-1} \mathrm{~cm}^{-2} \mathrm{~K}^{-1} \mathrm{Torr}^{-1}\right), K D$ is the parameter describing the pressure-dependent heat transfer (Torr ${ }^{-1}$ ) by gas conduction, and $P$ is the applied chamber pressure (Torr).

Table I. Process Parameters for the Sublimation Experiments

\begin{tabular}{|c|c|c|c|c|}
\hline Phase & $\begin{array}{l}\text { Temperature } \\
\text { gradient } \\
{\left[{ }^{\circ} \mathrm{C} / \mathrm{min}\right]}\end{array}$ & $\begin{array}{l}\text { Shelf } \\
\text { temperature } \\
\text { setpoint }\left[{ }^{\circ} \mathrm{C}\right]\end{array}$ & $\begin{array}{l}\text { Time at shelf } \\
\text { temperature } \\
\text { setpoint } \\
\text { [min] }\end{array}$ & $\begin{array}{l}\text { Chamber } \\
\text { pressure } \\
\text { setpoint } \\
\text { [mTorr] }\end{array}$ \\
\hline \multirow[t]{3}{*}{ Freezing } & 1 & +5 & 15 & - \\
\hline & 1 & -5 & 15 & - \\
\hline & 1 & -40 & Variable* & - \\
\hline Drying & 2 & -10 & Variable $^{+}$ & $\begin{array}{ll}50, & 200, \\
100 & 400\end{array}$ \\
\hline
\end{tabular}

*Freezing times were adjusted for scheduling convenience. A minimum hold time of $60 \mathrm{~min}$ for $20-\mathrm{mL}$ vials and $180 \mathrm{~min}$ for 50-mL vials was used to ensure temperature equilibration

+ Drying times were adapted based on sublimation rates for each vial system. The experiments were performed with approximately $40 \%$ ice sublimation for each vial type
The mean free path of water molecules $\left(\lambda_{\mathrm{H} 20}\right)$ and Knudsen numbers $(K n)$ were calculated for all vial systems to assess the flow character of gas molecules between the shelf and the vial bottom. $\lambda_{\mathrm{H} 20}$ was calculated according to Eq. 3 (29):

$\lambda_{H 20}=\frac{R \times T}{\sqrt{2} \times \pi \times d^{2} \times N_{A} \times P}$

where $R$ is the universal gas constant $\left(\mathrm{J} \mathrm{K}^{-1} \mathrm{~mol}^{-1}\right), T$ is the absolute gas temperature $(\mathrm{K}), d$ is the diameter of the gas molecule $(\mathrm{m}), N_{\mathrm{A}}$ is the Avogadro constant $\left(\mathrm{mol}^{-1}\right)$, and $P$ is the chamber pressure $(\mathrm{Pa})$. A diameter of $4.18 \times 10^{-10} \mathrm{~m}$ was taken from the literature for a spherical equivalent to water molecules in the gas phase (30). The temperatures at the vial bottom ranged from $-42^{\circ} \mathrm{C}$ to $-25^{\circ} \mathrm{C}$ between experiments while the shelf temperature was constant at $-5^{\circ} \mathrm{C}$ or $-10^{\circ} \mathrm{C}$, respectively. $\lambda_{\mathrm{H} 20}$ was calculated for an intermediate temperature value of $-20^{\circ} \mathrm{C}$ for all pressure setpoints. $K n$ was calculated based on $\lambda_{\mathrm{H} 20}$ and $l_{\text {eff }}$ values according to Eq. 4 (31):

$K n=\frac{\lambda_{H 20}}{l_{\text {eff }}}$

\section{Primary Drying Simulation}

Primary drying times of a $50 \mathrm{mg} / \mathrm{mL}$ mannitol solution were calculated with the LyoModelling Calculator for center vials of all vial systems and the investigated pressure setpoints to illustrate the impact of $K_{\mathrm{v}}$ differences on drying performance (17). The input parameters are shown in Table II. The fill volumes corresponded to a fill depth of $0.75 \mathrm{~cm}$ for each vial system. The resistance parameters were obtained from the material database of the calculator for a $50 \mathrm{mg} / \mathrm{mL}$ mannitol solution nucleated at $-15^{\circ} \mathrm{C}$. The shelf temperature was kept constant at $-20^{\circ} \mathrm{C}$ for all pressure setpoints for the purpose of this simulation. The results are based on input data and steady-state heat and mass transfer principles with the assumption that the pore morphology is preserved throughout primary drying. The results were used to illustrate how much of an impact changes in $K_{\mathrm{v}}$ could have on drying performance. For a more in-depth explanation of the input 
Table II. LyoModelling Calculator Input Data

\begin{tabular}{|c|c|c|c|c|c|c|}
\hline Input parameter & 20-mL BB & 20-mL PB1 & 20-mL PB2 & 50-mL PB1 & 50-mL PB2 & 20-mL ST \\
\hline Fill volume $(\mathrm{mL})$ & 5.16 & 5.16 & 5.16 & 10.89 & 10.89 & 4.49 \\
\hline Vial outer diameter $(\mathrm{cm})$ & 3.2 & 3.2 & 3.2 & 4.6 & 4.6 & 3.0 \\
\hline Shelf temperature $\left({ }^{\circ} \mathrm{C}\right)$ & \multicolumn{6}{|l|}{-20} \\
\hline Chamber pressure (mTorr) & \multicolumn{6}{|c|}{$50,100,200,400$} \\
\hline Solute concentration (\%) & \multicolumn{6}{|c|}{5} \\
\hline Resistance parameters & \multicolumn{6}{|c|}{$R_{0}=3.9, A_{1}=10, A_{2}=0.3$} \\
\hline Calculation tolerance (\%) & \multicolumn{6}{|c|}{0.0001} \\
\hline Solute material property & \multicolumn{6}{|l|}{ Crystalline } \\
\hline Divisions for computation & \multicolumn{6}{|l|}{10 slices } \\
\hline Area ratio & \multicolumn{6}{|l|}{1.2} \\
\hline Solution density $(\mathrm{g} / \mathrm{mL})$ & \multicolumn{6}{|l|}{1} \\
\hline Solute density (solid) $(\mathrm{g} / \mathrm{mL})$ & \multicolumn{6}{|l|}{1.5} \\
\hline Ice density $(\mathrm{g} / \mathrm{mL})$ & \multicolumn{6}{|l|}{0.918} \\
\hline Heat of sublimation $(\mathrm{cal} / \mathrm{g})$ & \multicolumn{6}{|l|}{660} \\
\hline Effective thermal conductivity ( $\mathrm{cal} \mathrm{cm}^{-1} \mathrm{~s}^{-1} \mathrm{~K}^{-1}$ ) & \multicolumn{6}{|c|}{0.0059} \\
\hline Vial heat transfer coefficient $\left(\mathrm{cal} \mathrm{s}^{-1} \mathrm{~cm}^{-2} \mathrm{~K}^{-1}\right)$ & \multicolumn{6}{|c|}{ User defined } \\
\hline
\end{tabular}

parameters or the LyoModelling Calculator, the reader is referred to the references $(17,32,33)$.

\section{RESULTS AND DISCUSSION}

\section{Geometrical Characterization}

Contact Area. The vial imprints in Fig. 2 showed minimal direct contact area of the vial bottom to the shelf surface. $A_{\mathrm{c}}$ values and the contact areas in relation to the total outer vial cross-sectional area $\left(A_{\mathrm{c}} / A_{\mathrm{v}}\right)$ are summarized in Table III. All vials except the $20-\mathrm{mL}$ PB2 and $20-\mathrm{mL}$ ST vials featured a stippled bottom that limits direct contact to punctual areas. A direct comparison of the $20-\mathrm{mL} \mathrm{BB}$ vial imprints to the $20-\mathrm{mL}$ $\mathrm{PB}$ variants showed higher heterogeneity of the $\mathrm{BB}$ vials within each imprint. Despite the similar $A_{\mathrm{c}}$ value of $20-\mathrm{mL}$ $\mathrm{BB}$ and 20-mL PB1, one-quarter of the vial base showed superior direct contact over the rest for the $\mathrm{BB}$ vials. The flatter bottom design of the 20-mL PB2 and 20-mL ST vials significantly improved the direct contact area with the shelf below the vial. However, this improved contact area came at the cost of compromised homogeneity. The middle imprint of the 20-mL PB2 vials showed an example of a superior contact area of two opposing sides compared to the ones in between. Similarly, the contact area on the outside of vial was more heterogeneous for 20-mL ST vials as well. Comparison of the 50 -mL vial imprints showed that the different glass compositions affected the direct contact area. The 50-mL PB2 vials showed a lower contact area than the $50-\mathrm{mL}$ PB1 vials. A comparison of the $A_{c} / A_{\mathrm{v}}$ values in Table III showed a decrease of the relative contact area with increasing vial size. While the glass compositions or vial sizes only led to small differences in $A_{\mathrm{c}} / A_{\mathrm{v}}$, the main factor influencing the direct contact area was the stippled or flat vial bottom design.

Vial Wall Thickness and Bottom Curvature. The lateral cuts in Fig. 3 showed clear differences in the homogeneity of the 20-mL BB vials compared to all PB vial types. The PB process led to an improved homogeneity of the vial wall thickness. The example image of the $20-\mathrm{mL} \mathrm{BB}$ vial in Fig. 3

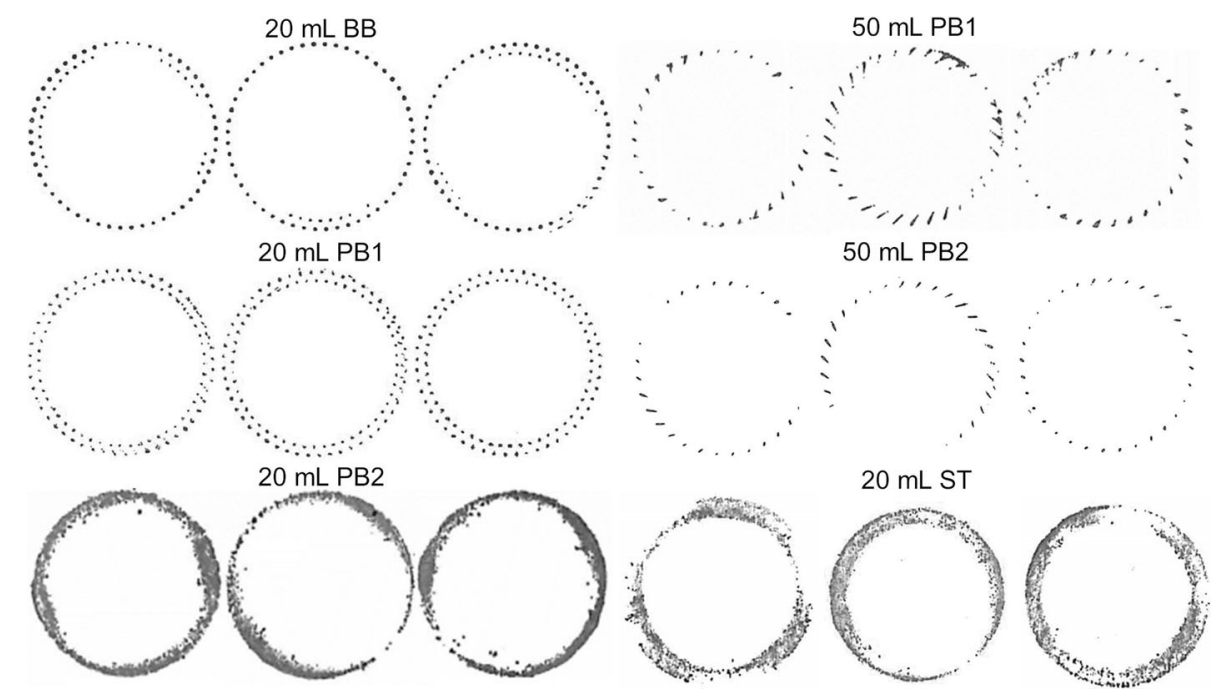

Fig. 2. Vial imprints of all investigated vial systems 
Table III. Geometrical Data of the Investigated Vial Systems

\begin{tabular}{lcrcc}
\hline Vial & $\mathrm{A}_{\mathrm{c}}\left(\mathrm{mm}^{2}\right)$ & \multicolumn{1}{c}{$A_{\mathrm{c}} / A_{\mathrm{v}}(\%)$} & $l_{\max }(\mathrm{mm})$ & $l_{\mathrm{eff}}(\mathrm{mm})$ \\
\hline 20-mL BB & $17.14 \pm 1.34$ & $2.12 \pm 0.17$ & $1.53 \pm 0.18$ & $1.11 \pm 0.03$ \\
20-mL PB1 & $17.64 \pm 1.15$ & $2.18 \pm 0.14$ & $1.39 \pm 0.09$ & $0.99 \pm 0.01$ \\
20-mL PB2 & $102.99 \pm 18.45$ & $12.73 \pm 2.28$ & $0.84 \pm 0.09$ & $0.65 \pm 0.02$ \\
50-mL PB1 & $25.45 \pm 9.49$ & $1.53 \pm 0.57$ & $2.32 \pm 0.20$ & $1.03 \pm 0.07$ \\
50-mL PB2 & $11.44 \pm 1.80$ & $0.69 \pm 0.11$ & $2.78 \pm 0.37$ & $1.30 \pm 0.12$ \\
20-mL ST & $93.40 \pm 11.87$ & $13.29 \pm 1.69$ & $0.31 \pm 0.11$ & $0.23 \pm 0.03$ \\
\hline
\end{tabular}

showed a pronounced difference between the left and the right vial wall near the bottom. The results of the geometrical measurements of these lateral cuts are summarized in Table III. Naturally, the 50-mL vials showed larger curvatures compared to the investigated $20-\mathrm{mL}$ vial systems. Significantly lower vial bottom curvatures were achieved with the design changes made to the $20-\mathrm{mL}$ PB2 vials compared to the $20-\mathrm{mL}$ PB1 vials. Additionally, the results showed that the manufacturing mold is not the only factor influencing the vial geometry. The 20-mL PB1 vials showed a trend towards a less pronounced vial bottom curvature compared to the $20-\mathrm{mL}$ $\mathrm{BB}$ vials, despite the same manufacturing molds. Comparison of both $50-\mathrm{mL}$ vial types showed a more pronounced curvature of the $50-\mathrm{mL}$ PB2 vials. A reason for these phenomena might be differences in the behavior of the glasses during manufacturing. The more heterogeneous glass distribution of the $\mathrm{BB}$ process might lead to differences in the cooling behavior of the vial during the manufacturing process. The different glass compositions could affect the cooling rates and thermal contraction coefficients. As expected, the 20-mL ST vials showed the smallest $l_{\max }$ and $l_{\text {eff }}$ values.

\section{Comparison of $K_{v}$ Values for Different Vial Systems}

An example of the individual $K_{\mathrm{v}}$ plots for the $20 \mathrm{~mL} \mathrm{BB}$ vials is shown in Fig. 4. $K_{\mathrm{v}}$ values for center vials were found homogenous across the shelf. As expected, edge vials showed overall higher $K_{\mathrm{v}}$ values and data were more scattered. This is due to the well-described "edge vial" effect and differences in the thermal environment of different edge vial positions (2). Edge vials can have between one and four empty adjacent vials depending on their position which contribute additional heat from the sides compared to filled vials.

The average $K_{v}$ values of center vials for all the investigated vial types in this study are shown in Fig. 5. The curves were obtained by fitting Eq. 2 to the data points. From a thermal perspective, optimized molded (10-mL EasyLyo ${ }^{\mathrm{TM}}$, SGD S.A., Puteaux, France) and serum tubing (10-mL TopLyo $^{\text {TM }}$, SCHOTT AG, Müllheim-Baden, Germany) vials were replotted from Hibler et al. (2) for comparison. All vial types showed a typical non-linear increase in $K_{\mathrm{v}}$ with increasing chamber pressure.

Slightly lower $K_{\mathrm{v}}$ values were observed for the $20-\mathrm{mL}$ BB vials compared to the 20-mL PB1 vials with identical designs. A trend towards a larger gap in $K_{\mathrm{v}}$ could be observed with increasing chamber pressure. The fact that the difference between the $20-\mathrm{mL} \mathrm{BB}$ and $20-\mathrm{mL}$ PB1 vials is pressuredependent showed that differences in gas conductive heat transfer are the cause of this. The $20-\mathrm{mL}$ PB2 vials showed

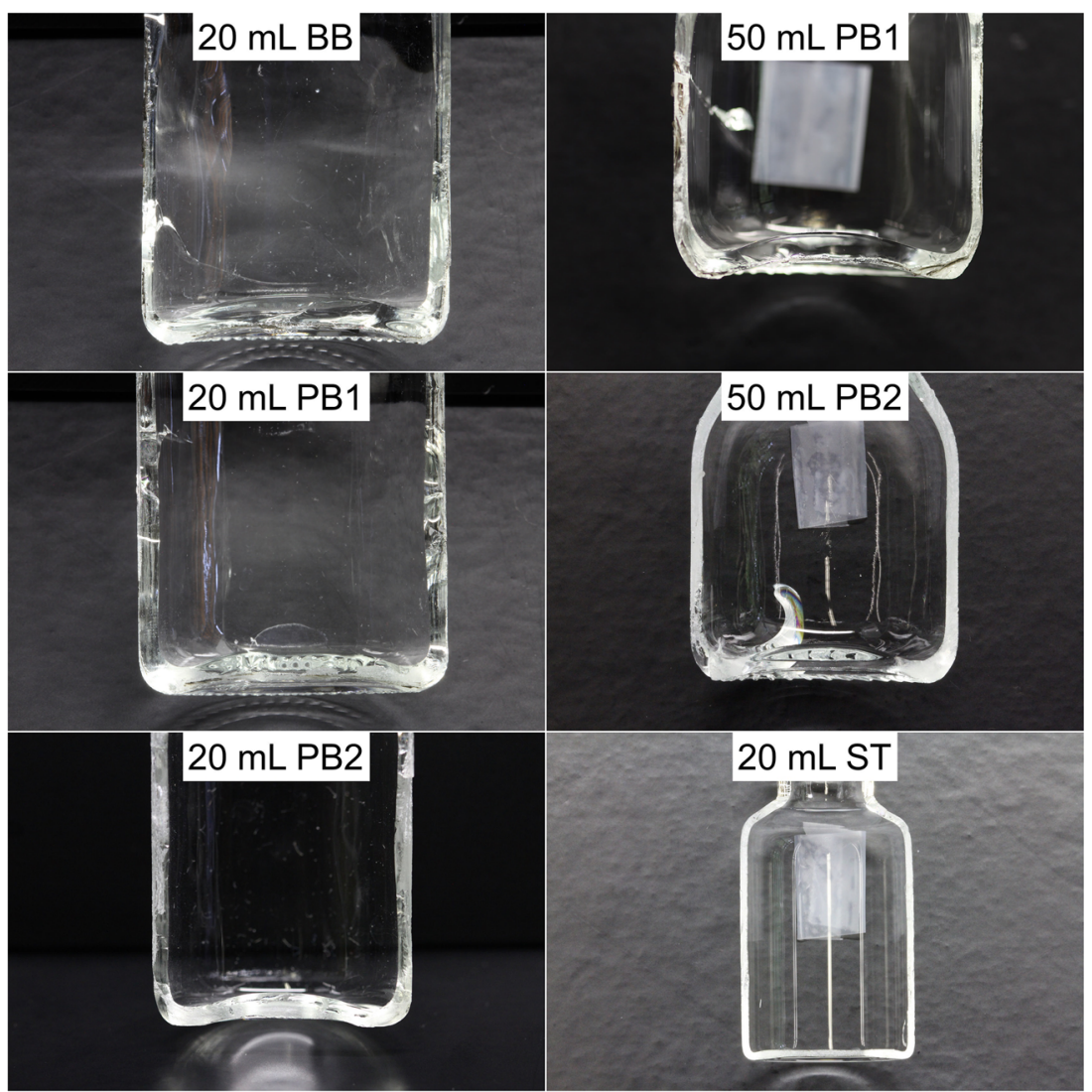

Fig. 3. Example lateral cuts of the investigated vial systems 

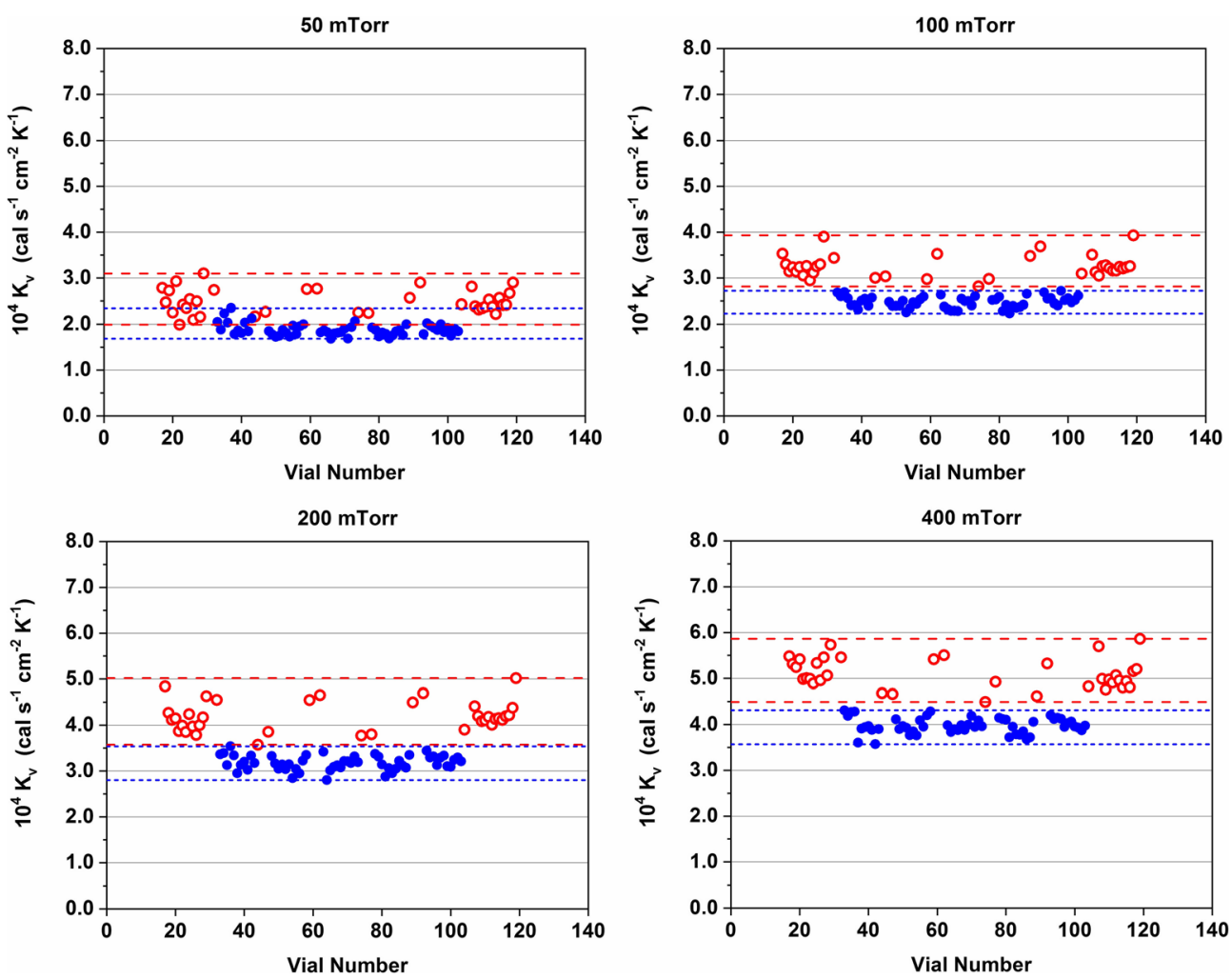

Fig. 4. Individual $K_{v}$ values of center (blue) and edge vials (red) at different pressure setpoints for the $20-\mathrm{mL}$ BB vials. The dashed and dotted lines show the maximum and minimum values for the center and edge vials, respectively

significantly improved heat transfer characteristics at all pressure setpoints compared to the $20-\mathrm{mL}$ PB1 vials. This highlighted the importance of vial geometry on thermal performance as previously described $(5,24)$. The 20-mL PB2 vials showed similar $K_{\mathrm{v}}$ values as the $10-\mathrm{mL}$ EasyLyo ${ }^{\mathrm{TM}}$ vials while the $10-\mathrm{mL}$ TopLyo ${ }^{\mathrm{TM}}$ serum tubing and $20-\mathrm{mL}$ ST vials overall showed more efficient heat transfer.

The $K_{\mathrm{v}}$ values of the 50 -mL PB1 vials were similar to the 20 -mL BB vial system despite the higher $l_{\max }$ of the $50-\mathrm{mL}$ PB1 vials. The $l_{\text {eff }}$ values, however, showed no significant difference between the two vial systems and could explain the similar

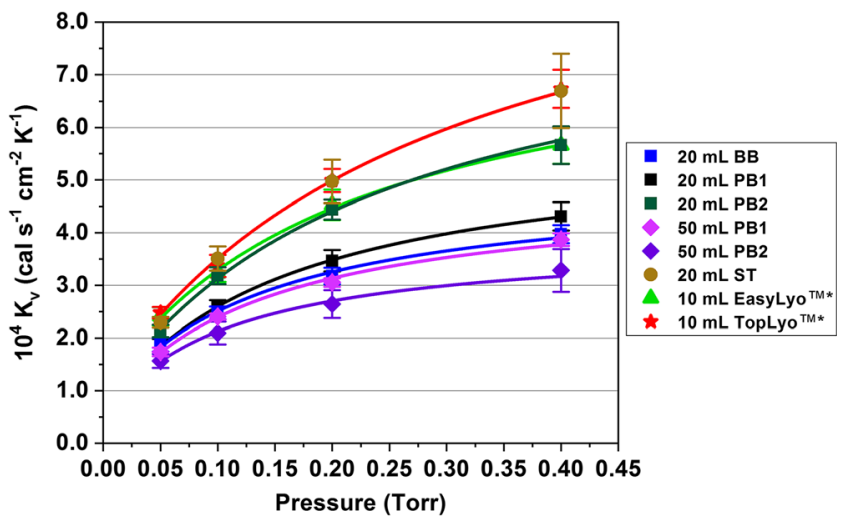

Fig. 5. Average $K_{\mathrm{v}}$ values of center vials for the different vial systems. The error bars represent the standard deviation. The curves were obtained by fitting Eq. 2 to the experimental data. *Data of $10-\mathrm{mL}$ EasyLyo $^{\mathrm{TM}}$ and $10-\mathrm{mL}$ TopLyo ${ }^{\mathrm{TM}}$ vials replotted from reference (2) with the authors' permission thermal behavior observed. This underlines the importance of assessing the entire vial bottom shape rather than facilitating only the description of $l_{\max }$ for a vial system. The geometrical differences observed for both the 50-mL PB1 and PB2 vials manifested themselves in significant differences in heat transfer. The different glass compositions resulted in overall lower $\mathrm{K}_{\mathrm{v}}$ values and an increase in heterogeneity of the 50-mL PB2 vials compared to the 50-mL PB1 vials.

\section{Influence of Shelf Load on the $K_{v}$ Distribution}

Individual $K_{\mathrm{v}}$ values for the experiments with partially and fully loaded shelves are shown in Fig. 6. The results clearly showed that the former edge vials performed identical compared to center vials in this experimental setup when the outside row was filled with water as well. Interestingly, the edge vials on the left and right side of the full array (vial numbers 1-16 and 120-135, respectively) could be divided into two groups. The $K_{\mathrm{v}}$ values of the edge vials on the right side of the full array were identical to the edge vials of the partially loaded shelf on that side while lower $K_{\mathrm{v}}$ values were determined for the edge vials on the left side of the full array compared to the configuration with empty vials on the outside.

The differences between the left and right edge vials of the full array could be attributed to the metal frame surrounding the vials. On a fully loaded shelf with a metal frame, additional heat is supplied by direct contact and gas conduction by the warmer metal frame and radiation from the chamber walls. Due to the design of the shelves, metal 

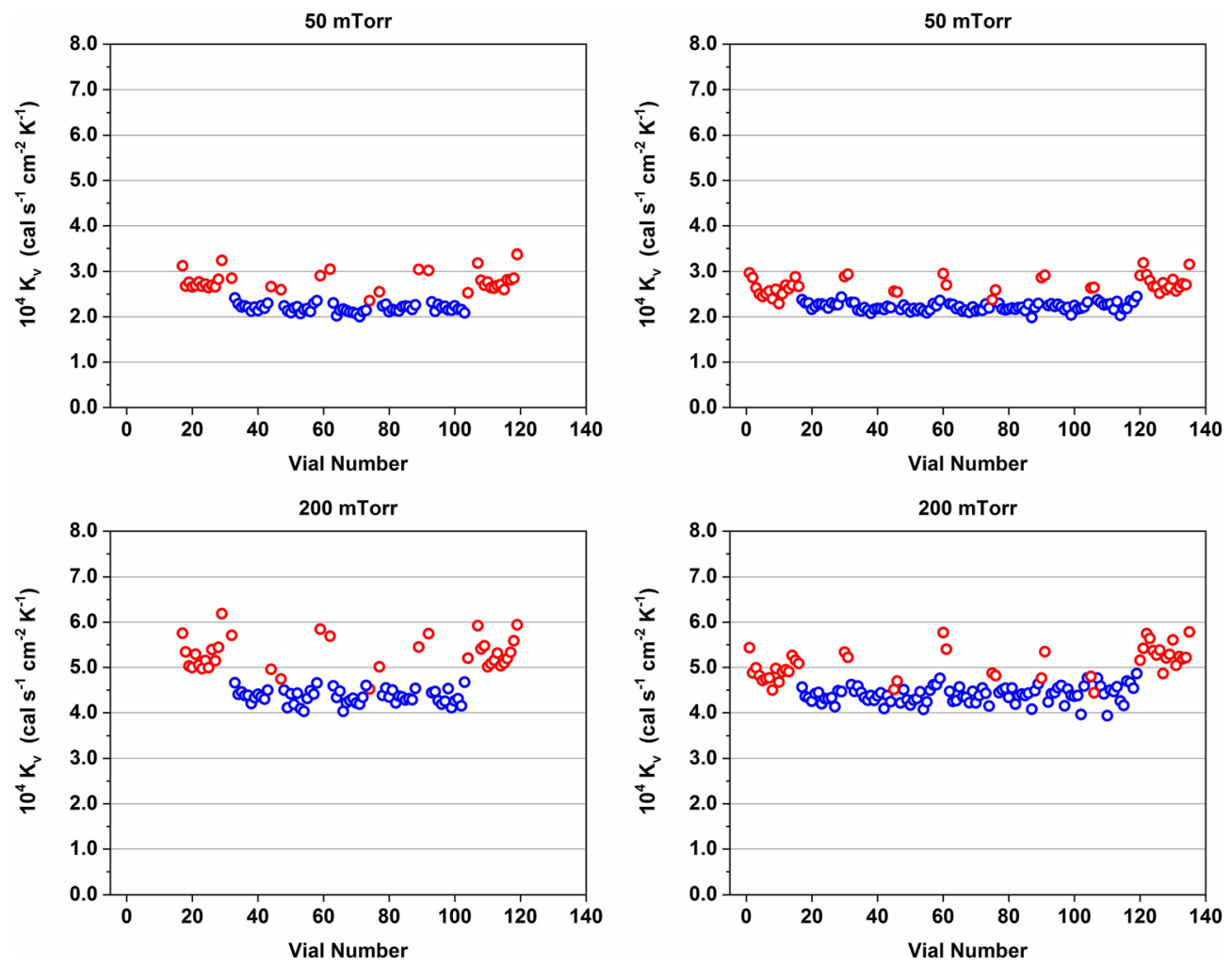

Fig. 6. Overview of individual $K_{\mathrm{v}}$ values of center (blue) and edge vials (red) at 50 and 200 mTorr for packaging arrays with an empty row of vials on the outside and all vials filled. Data obtained with the 20-mL PB2 vials

frame, and vials, only the vials on the left side of the array were in direct contact with the metal frame in these experiments. Consequently, the vials on the right side of the full array were less shielded by the metal frame and exposed to more radiation from the freeze-dryer chamber wall compared to the left side.

The paradigm that empty vials surrounding the product vials can reduce the edge vial effect is frequently encountered in the literature and was also adopted in this study for comparability $(2,34)$. The use of an empty row of vials on the outside of the vial array in conjunction with a metal frame did not influence the thermal behavior of center vials in our experimental setup. The thermal behavior of edge vials was dependent on the number of filled vials surrounding them and whether they were in direct contact with the metal frame or not. It should be noted that the edge vial effect is also dependent on $T_{\mathrm{s}}$. A more pronounced edge vial effect has been reported for lower $T_{\mathrm{s}}$ values because of the larger temperature differential between the shelf and chamber door and walls (18). Consequently, the relatively high $T_{\mathrm{s}}$ setpoints of $-5^{\circ} \mathrm{C}$ and $-10^{\circ} \mathrm{C}$ used in this study may also have contributed to this observation.

\section{Fitting Parameter Analysis}

The KC and KD values obtained from fitting Eq. 2 to the experimental data are shown in Table IV.

Comparison of KC Values for the Investigated Vial Systems. KC, which represents the pressure-independent fraction of total heat transfer, was similar for the $20-\mathrm{mL} \mathrm{BB}$ and $20-\mathrm{mL}$ PB1 vials. A significantly higher $\mathrm{KC}$ value was determined for the $20-\mathrm{mL}$ PB2 vials. Because radiative heat transfer is largely dependent on the temperature of surfaces exposed to the vial, which are considered identical between vial types, the $\mathrm{KC}$ differences between different vial types are mainly influenced by the direct contact area at the vial bottom. A similar value for the 20-mL BB and 20-mL PB1 vials was expected because of the identical vial bottom design and similar vial imprints. The higher $\mathrm{KC}$ value for the $20-\mathrm{mL}$ PB2 or 20-mL ST vials clearly shows the benefit of the design change of the vial bottom to a flat surface with a larger direct contact area.

Both 50-mL vial systems showed lower $\mathrm{KC}$ values compared to the $20-\mathrm{mL}$ vials. This was the expected behavior of the larger vial system because $\mathrm{KC}$ is calculated in relation to the total vial area. As seen during the imprint tests, only a small ring on the outside of the vial base is in direct contact with the vial bottom. While the increase in vial diameter from 20 to $50 \mathrm{~mL}$ vials led to a pronounced increase in total cross-

Table IV. Pressure-Independent and Pressure-Dependent Heat Transfer Parameters of the Investigated Vial Systems

\begin{tabular}{lll}
\hline Vial & $10^{4} \mathrm{KC}\left(\mathrm{cal} \mathrm{s}^{-1} \mathrm{~cm}^{-2} \mathrm{~K}^{-1}\right)$ & $\mathrm{KD}\left(\mathrm{Torr}^{-1}\right)$ \\
\hline 20-mL BB & $0.62 \pm 0.07$ & $7.62 \pm 0.41$ \\
20-mL PB1 & $0.57 \pm 0.02$ & $6.41 \pm 0.06$ \\
20-mL PB2 & $0.79 \pm 0.04$ & $4.18 \pm 0.17$ \\
50-mL PB1 & $0.52 \pm 0.07$ & $7.69 \pm 0.42$ \\
50-mL PB2 & $0.43 \pm 0.05$ & $9.63 \pm 0.50$ \\
20-mL ST & $0.88 \pm 0.04$ & $3.10 \pm 0.20$ \\
\hline
\end{tabular}




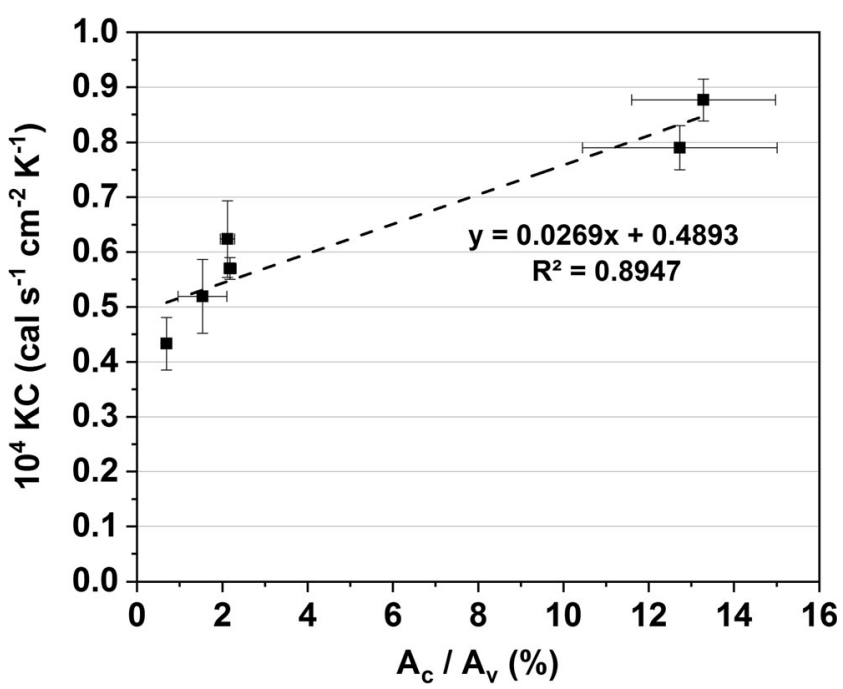

Fig. 7. $A_{\mathrm{c}} / A_{\mathrm{v}}$ values plotted against the pressure-independent heat transfer parameter KC. Errors bars represent standard deviation

sectional area, the contact area relative to total vial crosssectional area $A_{\mathrm{c}} / A_{\mathrm{v}}$ decreased. This led to a decrease in conductive heat transfer in relation to $A_{\mathrm{v}}$. $\mathrm{KC}$ values of both $50-\mathrm{mL}$ vial types were not significantly different. The minimally lower direct contact area of the $50-\mathrm{mL}$ PB2 vials observed during the imprint tests did not have a measurable effect on conductive and radiative heat transfer.

Contact Area and $K C$. The relative contact area $A_{\mathrm{c}} / A_{\mathrm{v}}$ is plotted against $\mathrm{KC}$ in Fig. 7. As expected, a trend towards higher $\mathrm{KC}$ values with increasing contact area was visible. Because of the small differences in relative contact area observed for most vial types in this study, the predictive capabilities of this calculation were limited, however. Scutella et al. (24) have shown that the calculation of the imprint area can be useful to predict heterogeneity due to pressure-independent heat transfer in $K_{\mathrm{v}}$ within one vial type. Our data confirmed the relationship between the contact area and $\mathrm{KC}$ but showed that empirical predictions for vials with different vial base designs remain difficult. The combination of $A_{\mathrm{c}} / A_{\mathrm{v}}$ and $\mathrm{KC}$ data of a vial with an identical base design (stippled or flat) could be useful as an approximation for $\mathrm{KC}$.

Comparison of KD Values for the Investigated Vial Systems. KD, which describes the pressure-dependent gas conduction heat transfer parameter, where lower values indicate more efficient heat transfer, showed significantly lower values for the 20-mL PB1 vials compared to the $20-\mathrm{mL}$ $\mathrm{BB}$ vials. The improved design for the $20-\mathrm{mL}$ PB2 vials further reduced the KD value. This observation confirms that the main cause of the difference observed between 20-mL BB and 20-mL PB1 $K_{\mathrm{v}}$ values was based on differences in gas conductive heat transfer. A reason for this could be the more heterogeneous wall thickness distributions for the 20-mL BB vials, which could lead to less efficient heat transfer because of small variations in the vial bottom curvature for the $20-\mathrm{mL}$ $\mathrm{BB}$ vials. Because the minimum $l_{\max }$ in a batch of molded vials is limited by the manufacturing mold, these heterogeneities could lead to slightly larger curvatures with compromised gas conductive heat transfer. Another effect of the heterogeneous wall thickness distributions could be non-ideal hexagonal packaging. If vials cannot be in full contact with neighboring vials because of varying wall thicknesses or asymmetry, the average separation distance between the vial bottom and the shelf could be compromised slightly. The greatly reduced KD value for the $20-\mathrm{mL}$ PB2 vials showed the benefit the reduction of the vial bottom curvature had on gas conductive heat transfer. The lower vial bottom curvature of the 20-mL ST vials resulted in a further reduction of KD.

The $50-\mathrm{mL}$ PB1 vials and $20-\mathrm{mL}$ BB vials were equivalent in their $\mathrm{KD}$ values. Consequently, the offset between the $K_{v}$ curves observed for those two vial systems was only caused by their differences in pressure-independent heat transfer. The KD values clearly showed a difference between both $50-\mathrm{mL}$ vial systems. This observation agreed with the geometrical characterization and showed that the more pronounced bottom curvature of the 50-mL PB2 vials led to less efficient gas conductive heat transfer as evidenced by the higher KD value.

Vial Bottom Curvature and KD. The obtained KD parameters for each vial system are plotted against $l_{\max }$ and

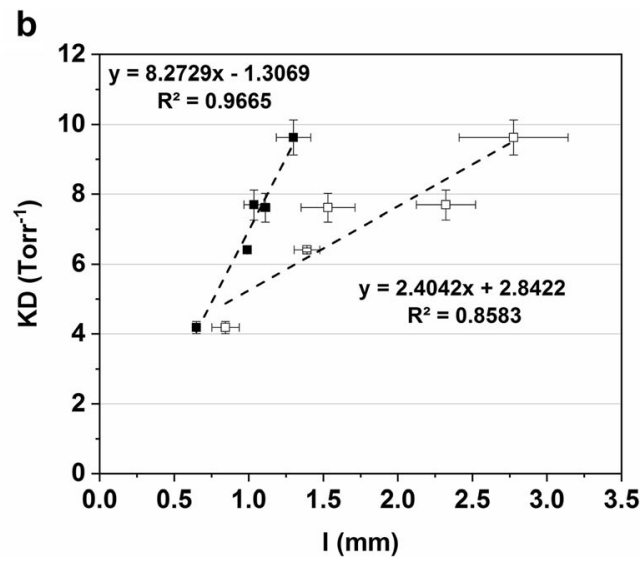

Fig. 8. $l_{\text {eff }}$ (black squares) and $l_{\max }$ (white squares) values plotted against the pressure-dependent heat transfer parameter KD. Error bars represent standard deviation 
Table V. $\lambda_{\mathrm{H} 20}$ and Knudsen Numbers for Each Vial System

\begin{tabular}{llllllll}
\hline Pressure (mTorr) & $\lambda_{\mathrm{H} 20}(\mathrm{~mm})$ & Kn 20-mL BB & Kn 20-mL PB1 & Kn 20-mL PB2 & Kn 50-mL PB1 & Kn 50-mL PB2 & Kn 20-mL ST \\
\hline 50 & 0.68 & 0.61 & 0.69 & 1.05 & 0.66 & 0.52 & 2.96 \\
100 & 0.34 & 0.31 & 0.34 & 0.52 & 0.33 & 0.26 & 1.48 \\
200 & 0.17 & 0.15 & 0.17 & 0.26 & 0.17 & 0.13 & 0.74 \\
400 & 0.08 & 0.07 & 0.08 & 0.12 & 0.08 & 0.06 & 0.35 \\
\hline
\end{tabular}

$l_{\text {eff }}$ in Fig. 8. Previous investigations of vial heat transfer mechanisms proposed a linear relationship between the mean separation distance of the vial bottom and shelf and KD $(2,5)$. Figure $8 \mathrm{a}$ showed a reasonable linear fit of the $l_{\max }$ values against KD. While a linear trend was visible, the $20-\mathrm{mL} B B$ vials $\left(l_{\max }=1.53 \pm 0.18 \mathrm{~mm}\right)$ and the $50-\mathrm{mL}$ PB1 vials $\left(l_{\max }=2.32 \pm\right.$ $0.20 \mathrm{~mm}$ ) showed a great offset between data and fitted model. The reason for this is that the vial bottom topology was not uniform. Depending on the manufacturing molds, two vial types with the same $l_{\max }$ could have large differences in the shape of the vial bottom curvature which could not be reliably described by $l_{\text {max }}$. The calculated $l_{\text {eff }}$ values provided an improved linear fit to the KD values. It should be noted that this observation was made for a relatively large variety of vial bottom curvatures. An overview of $\mathrm{Kn}$ for all vial types at the evaluated pressures is shown in Table V. Most vial systems were found in the lower transition flow regime $(0.1<\mathrm{Kn}<1,31)$. However, higher $\mathrm{Kn}$ values could be observed for the 20-mL ST vials compared to the other vials. The linear fit of $l_{\text {eff }}$ to KD was greatly improved when only vials with similar Kn values were compared (Fig. 8b). This could indicate that this calculation method was more accurate within a certain range of $\mathrm{Kn}$ values to avoid changes in the flow regime influencing the KD dependency on the separation distance. This conclusion is supported by the fact that the dependency of gas conductive heat transfer on the separation distance diminishes with increasing $\mathrm{Kn}$ (35). Based on our data, it seems reasonable to differentiate between molded and tubing vials for improved predictive capabilities. However, more data on tubing vials is necessary to further elucidate this.

As illustrated above, the proposed method of the $l_{\text {eff }}$ determination could be useful as a predictive parameter to calculate $\mathrm{KD}$ and $K_{\mathrm{v}}$ for molded vials. This determination would be less time-consuming compared to a gravimetric approach at multiple pressure setpoints. In contrast to the MTM, TDLAS, or AccuFlux ${ }^{\circledR}$ approaches described in the literature, it did not require special freeze-drying equipment and could be performed independently of the freeze-dryer (19-22). Our data proved a great correlation of $l_{\text {eff }}$ with KD across different vial sizes and designs for molded vials.

\section{LyoModelling Calculator Results for Primary Drying Times}

The simulated primary drying times for all investigated vial systems are summarized in Table VI. Comparison of the 20-mL BB and 20-mL PB1 vials showed that while the PB process had a clear effect on $K_{\mathrm{v}}$ and $\mathrm{KD}$, the differences observed between the two manufacturing processes were likely not practically relevant for drying performance. The simulated differences in primary drying times were between 1 and $6 \%$ for the two vial systems and would likely be overshadowed by intervial heterogeneity. The effect of the design changes between the $20-\mathrm{mL}$ PB1 and PB2 vials was much more pronounced and resulted in a reduction of primary drying time by $11-21 \%$. Comparison of the simulated data for the 20-mL PB1 and PB2 vials to the $K_{\mathrm{v}}$ data in Fig. 5 showed that the sublimation rate is very sensitive to changes in $K_{\mathrm{v}}$ at low pressures and the minimal differences observed in $K_{\mathrm{v}}$ at 50 mTorr resulted in pronounced and practically relevant differences in drying performance. Naturally, the $20-\mathrm{mL}$ ST vials featured the shortest primary drying times with a further reduction of $6-13 \%$ compared to the 20-mL PB2 vials.

The primary drying times calculated for the $50-\mathrm{mL}$ vial systems were $8-14 \%$ higher for the $50-\mathrm{mL}$ PB2 vials. Additionally, the observed increase in heterogeneity of the $K_{\mathrm{v}}$ values in Fig. 5 also translated into higher heterogeneity in primary drying performance with an increase of the relative standard deviation of primary drying time from approximately $2 \%$ for the $50-\mathrm{mL}$ PB1 vials to $5-10 \%$ for the $50-\mathrm{mL}$ PB2 vials.

\section{CONCLUSIONS}

The influence of different manufacturing techniques and glass compositions of molded vials on heat transfer characteristics has been investigated for the first time. The results of this study showed that the PB technique results in small improvements in gas conductive heat transfer compared to the BB technique. The glass composition has been found to affect the geometry of the vial bottom and gas conductive heat transfer. The use of empty vials as additional thermal

Table VI. LyoModelling Calculator Results for the Primary Drying Times of a $50 \mathrm{mg} / \mathrm{mL}$ Mannitol Solution at a Fill Depth of $0.75 \mathrm{~cm}$ and a $T_{\mathrm{s}}$ of $-20^{\circ} \mathrm{C}$

\begin{tabular}{|c|c|c|c|c|c|c|}
\hline \multirow[t]{2}{*}{ Pressure (mTorr) } & \multicolumn{6}{|c|}{ Primary drying time $(\mathrm{h})$} \\
\hline & 20-mL BB & 20-mL PB1 & 20-mL PB2 & 50-mL PB1 & 50-mL PB2 & 20-mL ST \\
\hline 50 & $40.3 \pm 1.8$ & $40.8 \pm 1.8$ & $36.9 \pm 1.1$ & $43.5 \pm 1.0$ & $46.9 \pm 2.4$ & $34.7 \pm 0.9$ \\
\hline 100 & $37.7 \pm 1.3$ & $36.5 \pm 1.0$ & $31.8 \pm 0.9$ & $39.3 \pm 0.6$ & $43.6 \pm 3.7$ & $29.5 \pm 1.1$ \\
\hline 200 & $40.3 \pm 1.4$ & $37.9 \pm 1.3$ & $32.2 \pm 0.8$ & $42.3 \pm 0.7$ & $47.2 \pm 3.4$ & $29.6 \pm 1.4$ \\
\hline 400 & $59.3 \pm 1.9$ & $56.0 \pm 2.2$ & $46.4 \pm 1.5$ & $61.8 \pm 1.3$ & $70.5 \pm 7.0$ & $40.6 \pm 2.3$ \\
\hline
\end{tabular}


shielding did not influence the thermal behavior of center vials. Edge vial performance was dependent on the number of filled vials surrounding them and whether they were in contact with the metal frame surrounding the array. The impact of the observed differences in $K_{\mathrm{v}}$ values on drying performance has been simulated. The calculated differences in primary drying time showed that the small improvements of the $\mathrm{PB}$ technique over the $\mathrm{BB}$ technique are likely not practically relevant while the vial design and glass composition showed a noticeable effect.

The determination of the contact area based on vial bottom imprints showed promising results for an approximation of the pressure-independent heat transfer parameter $\mathrm{KC}$ for vials with a similar vial bottom design. A method to determine $l_{\text {eff }}$ based on light microscopy as a more accurate description of the vial bottom geometry has been proposed. A great correlation between $l_{\text {eff }}$ and the pressure-dependent heat transfer parameter KD could be confirmed for molded vials. The determination of $l_{\mathrm{eff}}$ is a promising alternative to a time-consuming gravimetric $K_{\mathrm{v}}$ determination for different vial systems and could be a useful complementary tool to other methods of determining $K_{\mathrm{v}}$.

\section{ACKNOWLEDGMENTS}

The authors want to thank SGD for providing the vials for this study. SGD Pharma (Kipfenberg, Germany) is greatly acknowledged for their support with the lateral vial cuts and light microscopy measurements.

\section{FUNDING} DEAL.

Open Access funding enabled and organized by Projekt

Open Access This article is licensed under a Creative Commons Attribution 4.0 International License, which permits use, sharing, adaptation, distribution and reproduction in any medium or format, as long as you give appropriate credit to the original author(s) and the source, provide a link to the Creative Commons licence, and indicate if changes were made. The images or other third party material in this article are included in the article's Creative Commons licence, unless indicated otherwise in a credit line to the material. If material is not included in the article's Creative Commons licence and your intended use is not permitted by statutory regulation or exceeds the permitted use, you will need to obtain permission directly from the copyright holder. To view a copy of this licence, visit http://creativecommons.org/licenses/by/4.0/.

\section{REFERENCES}

1. Sacha GA, Saffell-Clemmer W, Abram K, Akers MJ. Practical fundamentals of glass, rubber, and plastic sterile packaging systems. Pharm Dev Technol. 2010;15(1):6-34. https://doi.org/ 10.3109/10837450903511178.

2. Hibler S, Wagner C, Gieseler H. Vial freeze-drying, part 1: new insights into heat transfer characteristics of tubing and molded vials. J Pharm Sci. 2012;101(3):1189-201. https://doi.org/10.1002/ jps.23004.

3. Bauer EJ. Container fabrication. In:Pharmaceutical packaging handbook. New York: Informa Healthcare USA, Inc.; 2009. p. 295-385. https://doi.org/10.3109/9781420012736.

4. Forcinio H. Selecting primary packaging for parenterals. Pharm Tech. 2018;42(7):46-50.

5. Pikal MJ, Roy ML, Shah S. Mass and heat transfer in vial freeze-drying of pharmaceuticals: role of the vial. J Pharm Sci. 1984;73(9):1224-37. https://doi.org/10.1002/jps.2600730910.

6. Ganguly A, Nail SL, Alexeenko A. Experimental determination of the key heat transfer mechanisms in pharmaceutical freezedrying. J Pharm Sci. 2013;102(5):1610-25. https://doi.org/ 10.1002/jps.23514.

7. Lienhard IV JH, Lienhard V JH. The general problem of heat exchange. In: A heat transfer textbook. Cambridge, Phlogiston Press; 2017. p. 1-140.

8. Giordano A, Barresi AA, Fissore D. On the use of mathematical models to build the design space for the primary drying phase of a pharmaceutical lyophilization process. J Pharm Sci. 2011;100:311-24. https://doi.org/10.1002/jps.22264.

9. Pisano R, Fissore D, Barresi AA, Rastelli M. Quality by design: scale-up of freeze-drying cycles in pharmaceutical industry. AAPS PharmSciTech. 2013;14(3):1137-49. https://doi.org/ 10.1208/s12249-013-0003-9.

10. Nail SL, Searles JA. Elements of quality by design in development and scale-up of freeze-dried parenterals. Int Biopharm. 2008;21(1):44-52.

11. Koganti VR, Shalaev E. Investigation of design space for freezedrying: use of modeling for primary drying segment of a freezedrying cycle. AAPS PharmSciTech. 2011;11(3):854-61. https:// doi.org/10.1208/s12249-011-9645-7.

12. Rambhatla S, Pikal MJ. Heat and mass transfer scale-up issues during freeze-drying, I: atypical radiation and the edge vial effect. AAPS PharmSciTech. 2003;4(2):22-31. https://doi.org/ 10.1208/pt040214.

13. Rambhatla S, Tchessalov S, Pikal MJ. Heat and mass transfer scale-up issues during freeze-drying, III: control and characterization of dryer differences via operational qualification tests. AAPS PharmSciTech. 2006;7(2):E61-70. https://doi.org/10.1208/ pt070239.

14. Pikal MJ, Bogner R, Mudhivarthi V, Sharma P, Sane P. Freezedrying process development and scale-up: scale-up of edge vial versus center vial heat transfer coefficients, $\mathrm{K}_{\mathrm{v}}$. J Pharm Sci 2016;105(11):3333-3343. https://doi.org/10.1016/j.xphs.2016.07.027.

15. Kuu WY, Nail SL. Rapid freeze-drying cycle optimization using computer programs developed based on heat and mass transfer models and facilitated by tunable diode laser absorption spectroscopy (TDLAS). J Pharm Sci. 2009;98(9):3469-82. https://doi.org/10.1002/jps.21813.

16. Chen X, Sadineni V, Maity M, Quan Y, Enterline M, Mantri RV. Finite element method (FEM) modelling of freeze-drying: monitoring pharmaceutical product robustness during lyophilization. AAPS PharmSciTech. 2015;16(6):1317-26. https:// doi.org/10.1208/s12249-015-0318-9.

17. Pikal MJ, Bogner R, Labriola R. LyoModelling Calculator. 2017. In: SP scientific LyoTools [internet]. Warminster: SP Industries, Inc. Available from: https://www.spscientific.com/ LyoCalc/Lyocalculator.html (Accessed 4 Jun 2020).

18. Wegiel LA, Ferris SJ, Nail SL. Experimental aspects of measuring the vial heat transfer coefficient in pharmaceutical freeze-drying. AAPS PharmSciTech. 2018;19(4):1810-7. https:// doi.org/10.1208/s12249-018-0998-z.

19. Tang XC, Nail SL, Pikal MJ. Evaluation of manometric temperature measurement (MTM), a process analytical technology tool in freeze drying, part III: heat and mass transfer measurement. AAPS PharmSciTech. 2006;7(4):97-E111. https:// doi.org/10.1208/pt070497.

20. Kuu W, Nail SL, Sacha GA. Rapid determination of vial heat transfer parameters using tunable diode laser absorption spectroscopy (TDLAS) in response to step-changes in pressure set-point during freeze-drying. J Pharm Sci. 2009;98(3):1136-54. https://doi.org/10.1002/jps.21478.

21. Schneid SC, Gieseler H, Kessler WJ, Pikal MJ. Non-invasive product temperature determination during primary drying using 
tunable diode laser absorption spectroscopy. J Pharm Sci. 2009;98(9):3406-18. https://doi.org/10.1002/jps.21522.

22. Thompson TN, Wang Q, Reiter C. Developing Transferable Freeze Drying Protocols Using Accuflux ${ }^{\circledR}$ and a MicroFD® ${ }^{\circledR} .05$ Feb 2017. In: Pharmahub resources [Internet]. Available from: https://pharmahub.org/resources/729 (Accessed 4 Jun 2020).

23. Cannon A, Shemeley K. Statistical evaluation of vial design features that influence sublimation rates during primary drying. Pharm Res. 2004;21(3):536-42. https://doi.org/10.1023/ B:PHAM.0000019309.23212.d3.

24. Scutellà B, Passot S, Bourlés E, Fonseca F, Tréléa IC. How vial geometry variability influences heat transfer and product temperature during freeze-drying. J Pharm Sci. 2017;106(3):770-8. https://doi.org/10.1016/j.xphs.2016.11.007.

25. Brülls M, Rasmuson A. Heat transfer in vial lyophilization. Int $\mathbf{J}$ Pharm. 2002;246:1-16. https://doi.org/10.1016/S03785173(02)00353-8.

26. Schneider CA, Rasband WS, Eliceiri KW. NIH to ImageJ: 25 years of image analysis. Nat Methods. 2012;9(7):671-5. https:// doi.org/10.1038/nmeth.2089.

27. Pikal MJ, Cardon S, Bhugra C, Jameel F, Rambhatla S, Mascarenhas WJ, et al. The nonsteady state modeling of freeze drying: in-process product temperature and moisture content mapping and pharmaceutical quality applications. Pharm Dev Technol. 2005;10(1):17-32. https://doi.org/10.1081/PDT-35869.

28. Pikal MJ. Use of laboratory data in freeze drying process design: heat and mass transfer coefficients and the computer simulation of freeze drying. J Parenter Sci Technol. 1985;39(3):115-39.

29. Hirschfelder JO, Curtiss CF, Bird RB. Molecular theory of gases and liquids. 1st ed. New York: Wiley; 1954.
30. Mortimer RG. Physical chemistry. 3rd ed. Burlington: Elsevier Academic Press; 2008.

31. Dongari N, Sharma A, Durst F. Pressure-driven diffusive gas flows in micro-channels: from the Knudsen to the continuum regimes. Microfluid Nanofluidics. 2009;6(5):679-92. https:// doi.org/10.1007/s10404-008-0344-y.

32. Bogner R. LyoModelling Calculator Introduction - A New Tool to Assist in Freeze-Drying Process Design. 30 Jun 2016. In: SP Scientific webinar archive [Internet]. Warminster: SP Industries, Inc. Available from: https://www.spscientific.com/Webinars/Archives/ (Accessed 4 Jun, 2020).

33. Bogner R. LyoModelling Calculator for Advanced Users - A New Cycle Modelling Tool. 12 Jul 2016. In: SP Scientific webinar archive [Internet]. Warminster: SP Industries, Inc. Available from: https://www.spscientific.com/Webinars/Archives/ (Accessed 4 Jun, 2020).

34. Tang XC, Pikal MJ. Design of freeze-drying processes for pharmaceuticals: practical advice. Pharm Res. 2004;21(2):191200. https://doi.org/10.1023/B:PHAM.0000016234.73023.75.

35. Bahrami M, Yovanovich MM, Culham JR. Thermal joint resistances of conforming rough surfaces with gas-filled gaps. J Thermophys Heat Trans. 2004;18(3):318-25. https://doi.org/ $10.2514 / 1.5480$.

Publisher's Note Springer Nature remains neutral with regard to jurisdictional claims in published maps and institutional affiliations. 